\title{
An Accurate Approximate Solutions of Multipoint Boundary Value Problems
}

\author{
N. R Anakira *l, M. M. Al-Shorman ${ }^{2}$, A. F. Jameel ${ }^{3}$ \\ 1,2 Department of Mathematics, Faculty of Science and Information Technology, Irbid National University, Jordan \\ ${ }^{3}$ School of Quantitative Sciences, College Of Art and Scinces, \\ Universiti Utara Malaysia (UUM), Sintok, 06010 Kedah, Malaysia
}

\begin{abstract}
The main objective of this paper is to obtain a new accurate approximate solutions for a kind of ordinary differential equations called multipoint boundary value problems by using simple modification of optimal homotopy asymptotic method (OHAM). This procedure is a well-performance for calculating a better approximate solutions using one-order of approximation comparing with other methods which need higher order of approximations to gives the same results. Some examples are presented to testify the accuracy and applicability of this procedure. Comparisons are made between the present procedure and the other methods.
\end{abstract}

Keywords: Multi-point boundary value problems, homotopy asymptotic method, Error estimate, ordinary differential equations.

2010 MSC No: 34K28, 35A24, 35F30

\section{Introduction}

Multi-point boundary value problems (BVPs) appear in a many fields of applied mathematics and physics. For instance, the vibrations of a guy wire of uniform cross section composed of $N$ parts different densities can be described by a multi-point BVP which was explained by Moshiinsky 11. In fact, Multi-point BVPs arise in the mathematical modelling of viscoelastic and inelastic flows, deformation of beams and plate deflection theory 22. Many approximated analytical or numerical methods have been used to find solutions of multi-point BVPs, Urabe 3 applied Chebyshev series to approximate solutions of nonlinear first-order multi-point BVPs, An efficient technique to find semi-analytical solutions for higher order multi-point boundary value problems is presented to solve general multi-point BVPs by Kheybari and Darvishi [4, Also, based on the differential transform method an efficient algorithm was successfully applied to obtain approximate solutionof multi-point boundary value problems by Xie 5 .

Real world physical problems are generally described by differential equations especially BVPs or Multipoint BVPs, various numerical or approximated method were utilized for solving these type of differential equations, like Finite Difference Method [6] and homotopy perturbation and variational iteration method [7, A six-step Block Unification $[8]$ and so on. Many researchers have shown a great deal of interest on the approximate analytical solution for a wide classes of differential eqautions in the last few years using different procedures, one of the well-known powerful and efficient procedures for solving different types of differential equations is OHAM. In 2008, Marinca and Herisanu suggested the so-called optimal homotopy asymptotic method (OHAM) based on the homotopy equation

\footnotetext{
${ }^{*}$ Corresponding author. N. R Anakira ${ }^{1}$ alanaghreh_nedal@yahoo.com, Tel: 0060186615297
} 
in a series of papers [9, 10, 11] for the approximate solutions of nonlinear problems. This procedure give us with a convenient way to control the convergence of approximation series and demonstrates its validity and potential efficiency to solve a wide class of problems in applied science and engineering and also valid for small parameters. In the last few years, OHAM and its modifications has been applied successfully to solve many types of differential equations 12, 13, 14, 15, 16, 17, 18, 19, 20, 21.

In this paper,we will expand the application of OHAM by using simple modification to obtain a new accurate approximate analytic solution of multipoint boundary value problems throughout only one-order of approximation and comparing it with higher order of approximation using the same method 21. The procedure is directly applied without any linearization and discretizations or splitting the non-homogeneous term. The structure of this paper is formulated as follows: Section 2 is devoted to the analysis of the proposed method, in Section 3, two examples are employed to illustrate the accuracy and computational efficiency of this procedure, and finally, conclusions are given in the last section.

\section{Method of Solution}

To explain the basic idea of OHAM [9, 22, we consider the following differential equation

$$
L(u(x))+g(x)+N(u(x))=0, \quad B\left(u, \frac{\mathrm{d} u}{\mathrm{~d} x}\right)=0,
$$

where $L$ is the chosen linear operator, $N$ is the linear or nonlinear operator, $u(x)$ is an unknown function, $x$ denotes an independent variable, $g(x)$ is a known function and $B$ is a boundary operator.

According to the basic idea OHAM we construct a homotopy $h(v(x, p), p): R \times[0,1] \rightarrow R$ which satisfies

$$
\begin{aligned}
(1-p)\left[L(v(x, p))-u_{0}(x)\right] & =H(p)[L(v(x, p))+g(x)+N(v(x, p))], \\
B\left(v(x, p), \frac{\partial v(x, p)}{\partial x}\right) & =0
\end{aligned}
$$

where $x \in R$ and $p \in[0,1]$ is an embedding parameter, $H(p)$ is a nonzero auxiliary function for $p \neq 0, H(0)=0$ and $v(x, p)$ is an unknown function. Obviously, when $p=0$ and $p=1$ it holds that $v(x, 0)=u_{0}(x)$ and $v(x, 1)=u(x)$ respectively. Thus, as $p$ varies from 0 to 1 , the solution $v(x, p)$ approaches from $u_{0}(x)$ to $u(x)$ where $u_{0}(x)$ is the initial guess that satisfies the linear operator and the boundary conditions

$$
L\left(u_{0}(x)\right)=0, \quad B\left(u_{0}, \frac{\mathrm{d} u_{0}}{\mathrm{~d} x}\right)=0 .
$$

The auxiliary function $H(p)$ will be chosen in the following form

$$
H(p)=\sum_{m=1}^{k}\left(C_{m} * x^{m-1}\right) * p,
$$

where $C_{1}, C_{2}, C_{3}, \ldots$ are called the convergent control parameters which can be determined later.

To get an approximate solution, we expand $v\left(x, p, C_{i}\right)$ in Taylor's series about $p$ in the following manner,

$$
v\left(x, p, C_{i}\right)=u_{0}(x)+\sum_{k=1}^{\infty} u_{k}\left(x, C_{1}, C_{2}, \ldots, C_{k}\right) p^{k} .
$$

Substituting Eq.(5) into Eq.(2) and equating the coefficient of like powers of $p$, we obtain the following linear equations. The zeroth-order problem is given by Eq.(3), the first-order problem is given in the following form

$$
L\left(u_{1}(x)\right)+g(x)=C_{1} N_{0}\left(u_{0}(x)\right), \quad B\left(u_{1}, \frac{\mathrm{d} u_{1}}{\mathrm{~d} x}\right)=0,
$$

where $N_{m}\left(u_{0}(x), u_{1}(x), \ldots, u_{m}(x)\right)$ is the coefficient of $p^{m}$ in the expansion of $N(v(x, p))$ about the embedding parameter $p$.

$$
N\left(v\left(x, p, C_{i}\right)\right)=N_{0}\left(u_{0}(x)\right)+\sum_{m=1}^{\infty} N_{m}\left(u_{0}(x), u_{1}(x), \ldots, u_{m}(x)\right) p^{m}
$$


It has been observed that the convergence of the series (5) depends upon the auxiliary constants $C_{1}, C_{2}, C_{3}, \ldots$ If it is convergent at $p=1$, one has

$$
v\left(x, C_{i}\right)=u_{0}(x)+\sum_{k=1}^{\infty} u_{k}\left(x, C_{1}, C_{2}, \ldots, C_{k}\right) .
$$

The result of the $m$ th-order approximation is given

$$
\tilde{u}\left(x, C_{1}, C_{2}, C_{3}, \ldots, C_{m}\right)=u_{0}(x)+\sum_{i=1}^{m} u_{i}\left(x, C_{1}, C_{2}, \ldots, C_{i}\right) .
$$

Substituting (9) into (1) yields the following residual

$$
\begin{aligned}
R\left(x, C_{1}, C_{2}, C_{3}, \ldots, C_{m}\right)= & L\left(\tilde{u}\left(x, C_{1}, C_{2}, C_{3}, \ldots, C_{m}\right)\right)+g(x) \\
& +N\left(\tilde{u}\left(x, C_{1}, C_{2}, C_{3}, \ldots, C_{m}\right)\right) .
\end{aligned}
$$

If $R=0$, then $\tilde{u}$ will be the exact solution. Generally such a case will not arise for nonlinear problems, but we can minimize the functional

$$
J\left(C_{1}, C_{2}, C_{3}, \ldots, C_{m}\right)=\int_{a}^{b} R^{2}\left(x, C_{1}, C_{2}, C_{3}, \ldots, C_{m}\right) d x,
$$

where $a$ and $b$ are the endpoints of the given problem. The unknown constants $C_{i}(i=1,2,3, \ldots, m)$ can identified from the conditions

$$
\frac{\partial J}{\partial C_{1}}=\frac{\partial J}{\partial C_{2}}=\cdots=\frac{\partial J}{\partial C_{m}}=0 .
$$

With these constants known, the approximate solution (of order $m$ ) is well determined.

\section{$3 \quad$ Numerical Examples}

To illustrate the validity and capability of the presented procedure, we shall consider the following two examples of multipoint two-points BVPs.

\subsection{Example 1}

Consider the following third order linear multipoint BVP [21, 23].

$$
u^{\prime \prime \prime}(x)-k^{2} u^{\prime}(x)+1=0, \quad u^{\prime}(0)=0, \quad u^{\prime}(1)=0, \quad u(0.25)=0 .
$$

The exact solution of this problem is given by

$$
\begin{aligned}
u(x)= & \frac{1}{k^{3}}\left(\sinh \left(\frac{k}{2}-\sinh ((k x))\right)+\frac{1}{k^{2}}\left(x-\frac{1}{2}\right)\right. \\
& +\frac{1}{k^{3}}\left(\cosh (k x)-\cosh \left(\frac{k}{2}\right)\right) \tanh \left(\frac{k}{2}\right)
\end{aligned}
$$

According to the OHAM formulation described in above section, we construct a homotopy equation in case of the physical constant $k=5$ in the form of

$$
\begin{aligned}
& (1-p)\left[\frac{\partial^{3} v(x ; p)}{\partial x^{3}}+1\right]=H(p)\left[\frac{\partial^{3} v(x ; p)}{\partial x^{3}}-25 \frac{\partial v(x ; p)}{\partial x}+1\right] \\
& B\left(v(x, p), \frac{\partial v(x, p)}{\partial x}\right)=0 .
\end{aligned}
$$

Now using Eq. 15. when $p=0$, it yields the zeroth-order problem as:

$$
u_{0}^{\prime \prime}(x)+1=0, \quad u^{\prime}(0)=0, \quad u^{\prime}(1)=0, \quad u(0.25)=0 .
$$


which has the solution

$$
u_{0}(x)=0.166667\left(-x^{3}+1.5 x^{2}-0.25\right) .
$$

Now, apply Eq.(6) to give the first-order problem as:

$$
\begin{aligned}
u_{1}{ }^{(3)}(x)= & 12.5 c_{10} x^{11}+12.5 c_{9} x^{10}-12.5 c_{10} x^{10}+12.5 c_{8} x^{9}-12.5 c_{9} x^{9}+12.5 c_{7} x^{8} \\
& -12.5 c_{8} x^{8}+12.5 c_{6} x^{7}-12.5 c_{7} x^{7}+12.5 c_{5} x^{6}-12.5 c_{6} x^{6}+12.5 c_{4} x^{5} \\
& -12.5 c_{5} x^{5}+12.5 c_{3} x^{4}-12.5 c_{4} x^{4}+12.5 c_{2} x^{3}-12.5 c_{3} x^{3}+12.5 c_{1} x^{2} \\
& -12.5 c_{2} x^{2}-12.5 c_{1} x+0, \quad u^{\prime}(0)=0, \quad u^{\prime}(1)=0, \quad u(0.25)=0 .
\end{aligned}
$$

Substituting the solution of Eq. (18) together with Eq.(17) into Eq. (9) with $m=1$, yields, the first orderapproximate solution in the following form

$$
\begin{aligned}
\widetilde{u}\left(x, C_{1}, \cdots C_{10}\right)= & 0.00572344 c_{10} x^{14}+0.00728438 c_{9} x^{13}-0.00728438 c_{10} x^{13} \\
& +0.0094697 c_{8} x^{12}-0.0094697 c_{9} x^{12}+0.0126263 c_{7} x^{11} \\
& -0.0126263 c_{8} x^{11}+0.0173611 c_{6} x^{10}-0.0173611 c_{7} x^{10} \\
& +0.0248016 c_{5} x^{9}-0.0248016 c_{6} x^{9}+0.0372024 c_{4} x^{8} \\
& -0.0372024 c_{5} x^{8}+0.0595238 c_{3} x^{7}-0.0595238 c_{4} x^{7} \\
& -0.104167 c_{3} x^{6}+0.104167 c_{3} x^{2}+0.0595238 c_{4} x^{2} \\
& +0.0372024 c_{5} x^{2}+0.0248016 c_{6} x^{2}+0.0173611 c_{7} x^{2} \\
& +0.0126263 c_{8} x^{2}+0.0094697 c_{9} x^{2}+0.00728438 c_{10} x^{2} \\
& +c_{2}\left(0.104167 x^{6}-0.208333 x^{5}+0.208333 x^{2}-0.0472005\right) \\
& +c_{1}\left(0.208333 x^{5}-0.520833 x^{4}+0.520833 x^{2}-0.104167\right) \\
& -0.0248791 c_{3}-0.0145612 c_{4}-0.00920371 c_{5}-0.00616891 c_{6} \\
& -0.00432949 c_{7}-0.00315271 c_{8}-0.002366 c_{9}-0.00182056 c_{10} \\
& +0.166667\left(-1 . x^{3}+1.5 x^{2}-0.25\right)
\end{aligned}
$$

Following the procedure described in section 2 on the domain between $a=0$ and $b=1$, using the residual error,

$$
R=\widetilde{u}^{\prime \prime \prime}\left(x, C_{1}, \cdots C_{10}\right)-25 \widetilde{u}^{\prime}\left(x, C_{1}, \cdots, C_{10}\right)+1 .
$$

The least-square method can be applied as

$$
J\left(C_{1}, C_{2}, \cdots C_{10}\right)=\int_{0}^{1} R^{2} d x
$$

and

Thus, the following optimal values of $C_{i}$ 's are obtained:

$$
\frac{d J}{d C_{1}}=\frac{d J}{d C_{2}}=\cdots \frac{d J}{d C_{10}}
$$

$$
\begin{array}{r}
C_{1}=-0.394646, \quad C_{2}=0.605372, \quad C_{3}=-1.03921, \\
C_{4}=1.04537, \quad C_{5}=-1.01292, \quad C_{6}=0.720373, \\
C_{7}=-0.468559, \quad C_{8}=0.209234, \quad C_{9}=-0.0650757, \\
C_{10}=0.00541865 .
\end{array}
$$

By considering these values our approximate solution becomes,

$$
\begin{aligned}
\widetilde{u}\left(x, C_{1}, \cdots, C_{10}\right)= & -0.0121071+0.0986614 x^{2}-0.166667 x^{3}+0.205545 x^{4} \\
& -0.208337 x^{5}+0.17131 x^{6}-0.124082 x^{7}+0.0765735 x^{8} \\
& -0.0429885 x^{9}+0.0206412 x^{10}-0.00855799 x^{11} \\
& +0.00259763 x^{12}-0.000513508 x^{13}+0.0000310133 x^{14}
\end{aligned}
$$


Table 1: Comparison of exact solution and OHAM solution for Example 1 in case of $k=5$

\begin{tabular}{|c|c|c|c|c|c|}
\hline & & & Absolute & $\begin{array}{l}\text { Absolute } \\
\text { Error } 21\end{array}$ & \\
\hline \multicolumn{6}{|c|}{$0-0.0121071-0.01210712 .19 \times 10^{-12} 1.3 \times 10^{-10} 6.65 \times 10^{-5}$} \\
\hline \multirow{2}{*}{\multicolumn{6}{|c|}{$\begin{array}{l}.2-0.0092222-0.00922221 .66 \times 10^{-12} 6.99 \times 10^{-9} 5.25 \times 10^{-5} \\
.4-0.0033202-0.00332024 .57 \times 10^{-12} 1.07 \times 10^{-8} 1.88 \times 10^{-5}\end{array}$}} \\
\hline & & & & & \\
\hline \multicolumn{3}{|c|}{$.60 .0033202 \quad 0.0033202$} & & & \\
\hline \multirow{2}{*}{\multicolumn{2}{|c|}{$\begin{array}{l}0.80 .0092222 \\
1.00 .0121071\end{array}$}} & 0.00 & & & \\
\hline & & 0.0121071 & $2.18 \times 10$ & & 10 \\
\hline
\end{tabular}

Table 2: Comparison of exact solution and OHAM solution for Example 1 in case of $k=10$

\begin{tabular}{|c|c|c|c|}
\hline $\begin{array}{c}\text { Exact } \\
\text { Solution }\end{array}$ & $\begin{array}{l}\text { OHAM } \\
\text { Solution }\end{array}$ & $\begin{array}{l}\text { Absolute } \\
\text { Error }\end{array}$ & $\begin{array}{l}\text { Absolute } \\
\text { Error } 23\end{array}$ \\
\hline $0.0-0.00400009$ & -0.00400009 & $3.61 \times 10^{-1}$ & $3.52 \times 10^{-5}$ \\
\hline $0.2-0.00286501$ & -0.00286501 & $1.88 \times 10^{-1}$ & $3.03 \times 10^{-5}$ \\
\hline $0.4-0.00098416$ & $4-0.00098416$ & $42.10 \times 10$ & $10^{-5}$ \\
\hline .60 .000984164 & 0.000984164 & $9.28 \times 10^{-}$ & $10^{-6}$ \\
\hline .80 .0028 & 0.0028 & $1.49 \times 10^{-}$ & $\times 10^{-5}$ \\
\hline 1.00 .00400009 & 0.00400009 & $3.79 \times 10^{-}$ & $2.40 \times 10^{-5}$ \\
\hline
\end{tabular}

When the physical constanr $k=10$ and following the same procedur as previously appied in case of $k=5$, we obtain the following first-order approximte solution

$$
\begin{aligned}
\widetilde{u}\left(x, C_{1}, \cdots, C_{10}\right)= & 0.0000310133 x^{14}-0.000513508 x^{13}+0.00259763 x^{12} \\
& -0.00855799 x^{11}+0.0206412 x^{10}-0.0429885 x^{9} \\
& +0.0765735 x^{8}-0.124082 x^{7}+0.17131 x^{6}-0.208337 x^{5} \\
& +0.205545 x^{4}-0.166667 x^{3}+0.0986614 x^{2}-0.0121071
\end{aligned}
$$

Tables 1 and 2 show the comparison between the present solution obtained by using first-order OHAM approximation and the numerical results obtained from higher-order of approximation using other methods including OHAM solutions of three-order of approximations.Fig1, represents the plots of the first-order OHAM approximation the the exact one. Runge Kutta method

(a)

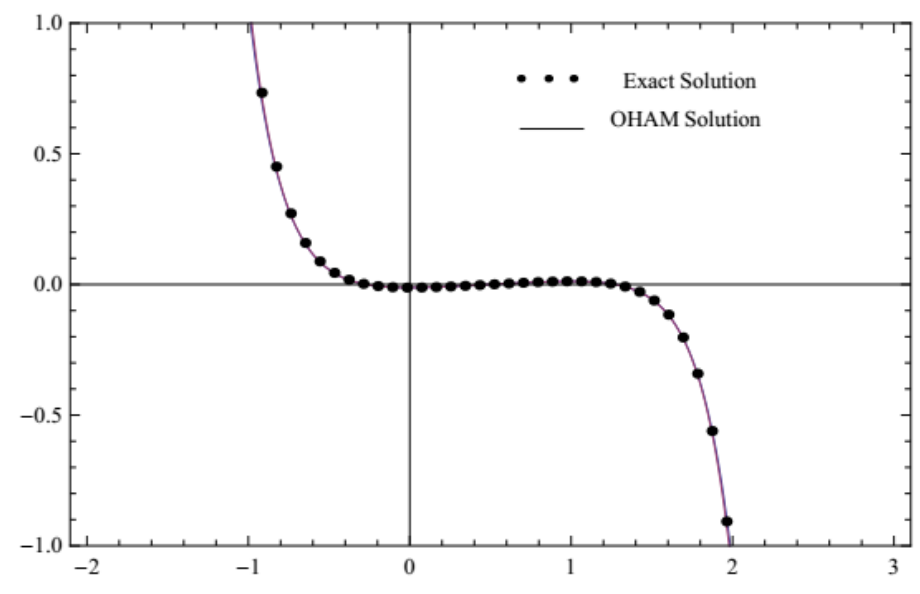


(b)

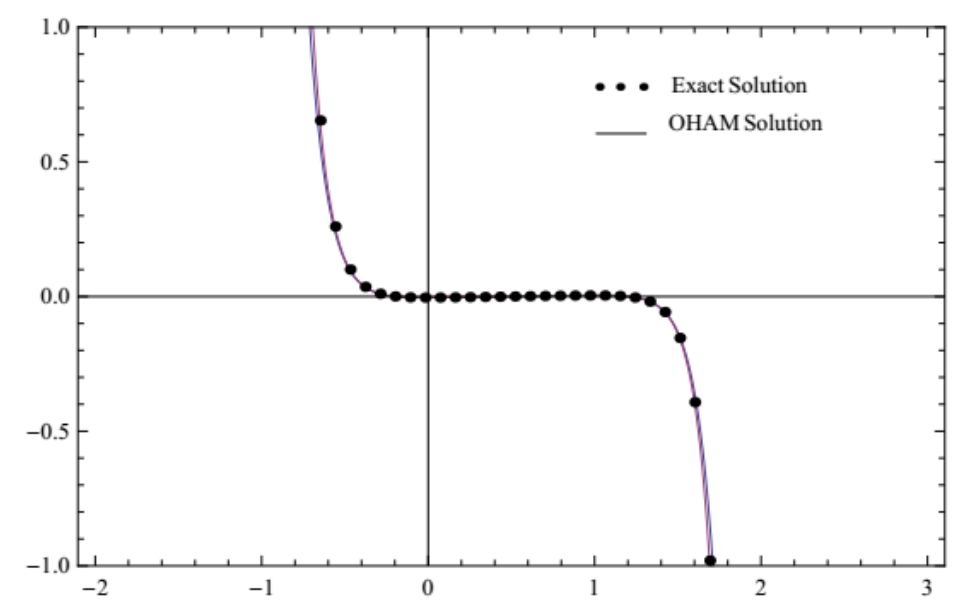

\subsection{Example 2}

Consider the following linear three-point non-local BVP [6],

$$
u^{\prime \prime \prime \prime}(x)-e^{x} u^{\prime \prime \prime}(x)+u(x)=1-e^{x} \cosh x+2 \sinh x,
$$

subject to the boundary conditions

$$
\begin{array}{rr}
u(0.25)=1+\sinh (0.25), \quad u^{\prime}(0.25)=\cosh (0.25), \\
u^{\prime \prime}(0.25)=\sinh (0.25), \quad u(0.5)-u(0.75)=\sinh (0.5)-\sinh (0.75)
\end{array}
$$

Using the method presented in Section 2, we obtain the first-order approximate solutions in the following form:

$$
\begin{aligned}
\widetilde{u}\left(x, C_{1}, C_{2}, C_{3}\right)= & -0.0003381 x^{9}+0.00048716 x^{8}-0.00710433 x^{7}+0.00403864 x^{6} \\
& +0.00673227 x^{5}-0.0276036 x^{4}-6.85065 x^{3}-5.68059 e^{-x} x^{2} \\
& +11.8151 e^{x} x^{2}-0.177518 e^{2 x} x^{2}-31.4 x^{2}-41.1715 e^{-x} x \\
& -103.409 e^{x} x+0.843612 e^{2 x} x-225.325 x-97.8443 e^{-x} \\
& +274.61 e^{x}-1.19609 e^{2 x}-174.569
\end{aligned}
$$

Table 3: comparison of exact solution and OHAM solution for Example 1.

\begin{tabular}{lcccc}
\hline$x$ & $\begin{array}{c}\text { Exact } \\
\text { Solution Solution }\end{array}$ & $\begin{array}{c}\text { OHAM } \\
\text { Error }\end{array}$ & $\begin{array}{c}\text { Absolute } \\
\text { Error }\end{array}$ & $\begin{array}{c}\text { Absolute } \\
\text { Error [5] }\end{array}$ \\
\hline $0.01 .0000000 .99994595 .41 \times 10^{-5}$ & $1.02 \times 10^{-4} 2.49 \times 10^{-6}$ \\
0.21 .20134 & 1.20134 & $4.31 \times 10^{-7} 5.33 \times 10^{-7} 1.95 \times 10^{-8}$ \\
0.41 .41075 & 1.41076 & $9.38 \times 10^{-6} 7.60 \times 10^{-6} 4.82 \times 10^{-6}$ \\
0.61 .63665 & 1.63672 & $6.5 \times 10^{-5}$ & $3.90 \times 10^{-5} 3.94 \times 10^{-6}$ \\
0.81 .88811 & 1.88808 & $2.94 \times 10^{-5} 2.42 \times 10^{-6} 3.34 \times 10^{-6}$ \\
1.02 .1752 & 2.17428 & $9.25 \times 10^{-4} 3.05 \times 10^{-4} 9.63 \times 10^{-5}$ \\
\hline
\end{tabular}

The obtained results are reported in Table 3. The performance of this procedure is very good and the result obtained during one-order of approximation is in a very good agreement to the exact solution comparing with other methods which needs higher order of approximation. This performance can be easily observed from this Table. The comparison of the exact solution and the approximate solution are shown in Figure 2. 


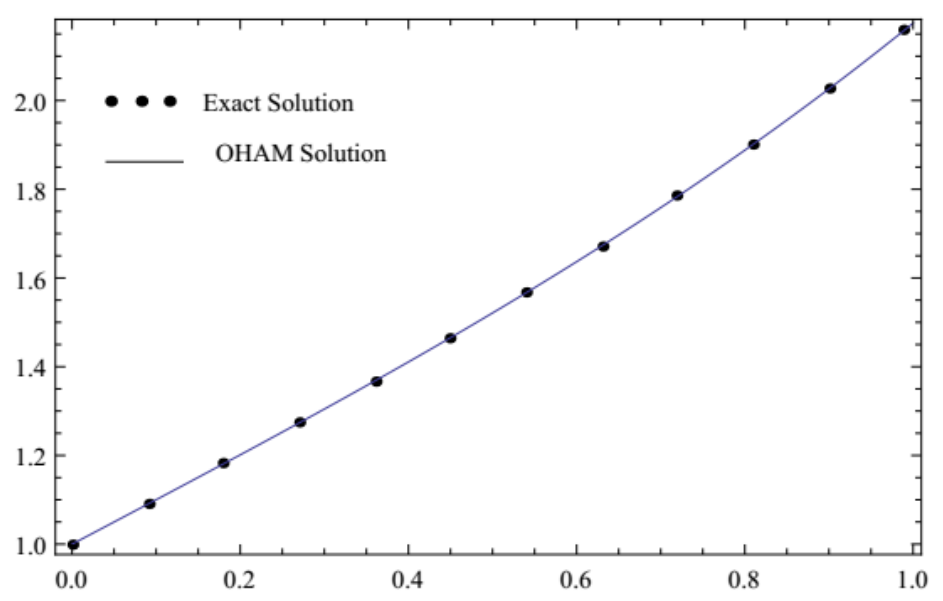

Figure 2: Exact and approximate solution using OHAM for Example 2.

\section{Conclusions}

In this research study, we proposed a new accurate approximate analytical solution for multipoint BVPs based on a simple modification of the optimal homotopy asymptotic method (OHAM) and comparing it with the results obtained by the same method previously and other method in literature. The examples presented in this work leads to the conclusion that the obtained results are quit accurate and are in a very good agreement with the analytical solution which is demonstrate and prove that this procedure is explicit, effective and accurate for this type of ordinary differential equations and can be easily applied to other differential equations.

\section{References}

[1] M. Moshinsky, Sobre los problemas de condiciones a la frontiera en una dimension de caracteristicas discontinuas. Bol. Soc. Mat. Mexicana 7 (1950): 1-25.

[2] Hajji, A. Mohamed. Multi-point special boundary-value problems and applications to fluid flow through porous media. Proceedings of International Multi-Conference of Engineers and Computer Scientists (IMECS 2009), Hong Kong. Vol. 31. 2009.

[3] Urabe, Minoru. Numerical solution of multi-point boundary value problems in Chebyshev series theory of the method. Numerische Mathematik 9.4 (1967): 341-366. https://doi.org/10.1007/bf02162424

[4] S. Kheybari, \& M. T. Darvishi, An efficient technique to find semi-analytical solutions for higher order multi-point boundary value problems. Applied Mathematics and Computation, 336 (2018), 76-93. https://doi.org/10.1016/j.amc.2018.04.074

[5] L. J. Xie, C. L. Zhou, \& S. Xu, A new algorithm based on differential transform method for solving multi-point boundary value problems. International Journal of Computer Mathematics, 93(6)2016, 981-994. https://doi.org/10.1080/00207160.2015.1012070

[6] P. K. Pandey, Finite Difference Method for Numerical Solution of Two Point Boundary Value Problems with Non-uniform Mesh and Internal Boundary Condition.General Letters in Mathematics, 4(1)2018, 6-12. https://doi.org/10.31559/glm2016.4.1.2

[7] F. Geng, \& M. Cui, Multi-point boundary value problem for optimal bridge design. International Journal of Computer Mathematics, 87(5)2010, 1051-1056. https://doi.org/10.1080/00207160903023573 
[8] M. I. Modebei, \& R. B. Adeniyi, six-step Block Unification Integrator for Numerical Solution of Fourth Order Boundary Value Problems. General Letters in Mathematics, 5(2)2018, 71-83. https://doi.org/10.31559/glm2018.5.2.2

[9] V. Marinca, N. Herisanu, C. Bota, and B. Marinca, An optimal homotopy asymptotic method applied to the steady flow of fourth-grade fluid past a porous plate, Applied Mathematics Letters, vol. 22, pp. 245-251, 2009. https://doi.org/10.1016/j.aml.2008.03.019

[10] V. Marinca, N. Herisanu, and I. Nemes, Optimal homotopy asymptotic method with application to thin film flow, Central European Journal of Physics, vol. 6, pp. 648-653, 2008. https://doi.org/10.2478/s11534-008-0061-x

[11] V. Marinca, and N. Herisanu, Application of optimal homotopy asymptotic method for solving nonlinear equations arising in heat transfer, International Communications in Heat 6 Mass Transfer, vol. 35, pp. 710-715, 2008. https://doi.org/10.1016/j.icheatmasstransfer.2008.02.010

[12] N. Ratib Anakira, A. K. Alomari, \& I. Hashim, Optimal homotopy asymptotic method for solving delay differential equations. Mathematical Problems in Engineering, 2013. https://doi.org/10.1155/2013/498902

[13] A. K. Alomari, N. R. Anakira, A. S. Bataineh, \& I. Hashim, Approximate solution of nonlinear system of BVP arising in fluid flow problem. Mathematical Problems in Engineering, 2013. https://doi.org/10.1155/2013/136043

[14] M. S. Awwad \& O. Y. Ababneh, Application of Optimal Homotopy Asymptotic Method for Solving Linear Boundary Value Problems Differential Equation.General Letters in Mathematics,1(3)2016, 81-94. https://doi.org/10.31559/glm2016.1.3.2

[15] M. Hamarsheh, A. I. Ismail, \& Z. Odibat, An analytic solution for fractional order Riccati equations by using optimal homotopy asymptotic method. Applied Mathematical Sciences, 10(23)2016, 1131-1150. https://doi.org/10.12988/ams.2016.6118

[16] N. R. Anakira, A. Jameel, A. K. Alomari, A. Saaban, M. Almahameed \& I. Hashim, Approximate solutions of multi-pantograph type delay differential equations using multistage optimal homotopy asymptotic method. Journal of Mathematical and Fundamental Sciences, 50(3)2018, 221-232.

[17] J. Biazar \& R. Montazeri, Optimal Homotopy Asymptotic and Multistage Optimal Homotopy Asymptotic Methods for Solving System of Volterra Integral Equations of the Second Kind. Journal of Applied Mathematics, 2019. https://doi.org/10.1155/2019/3037273

[18] N. R. Anakira, A. K. Alomari, A. F. Jameel \& I. Hashim, Multistage optimal homotopy asymptotic method for solving initial-value problems. Journal of Nonlinear Science and Applications, 9(4)2016, 1826-1843. https://doi.org/10.22436/jnsa.009.04.37

[19] N. R. Anakira, A. K. Alomari, A. F. Jameel \& I. Hashim, Multistage optimal homotopy asymptotic method for solving boundary value problems with robin boundary conditions. Far East Journal of Mathematical Sciences, 102(8)2017, 1727-1744. https://doi.org/10.17654/ms102081727

[20] N. Anakira, (2019, April). Solution of system of ordinary differential equations by optimal homotopy asymptotic method. In AIP Conference Proceedings (Vol. 2096, No. 1, p. 020023). AIP Publishing. https://doi.org/10.1063/1.5097820

[21] J. Ali, S. Islam, S. Islam, \& G. Zaman, The solution of multipoint boundary value problems by the optimal homotopy asymptotic method. Computers \& Mathematics with Applications, 59(6)2010, 2000-2006. https://doi.org/10.1016/j.camwa.2009.12.002

[22] N. R. Anakira, A. K. Alomari, \& I. Hashim, Numerical scheme for solving singular two-point boundary value problems. Journal of Applied Mathematics, 2013. https://doi.org/10.1155/2013/468909

[23] I. A. Tirmizi, E. H. Twizell \& Siraj-Ul-Islam, A numerical method for third-order non-linear boundary-value problems in engineering. International Journal of Computer Mathematics, 82(1)2005, 103-109. 